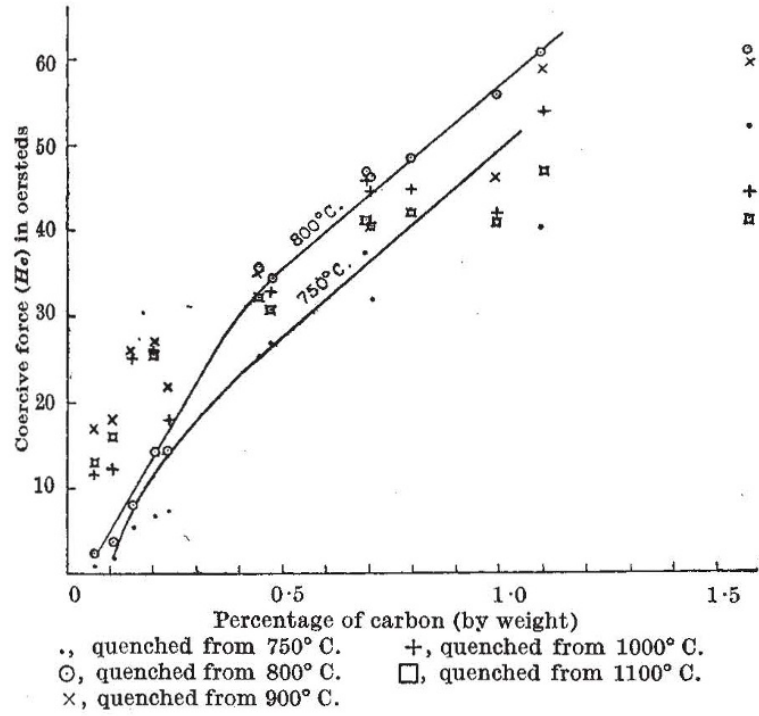

Fig. 3.

a coercimeter, used for the rapid determination of carbon in open-hearth steels, designed by Rogers ${ }^{2}$ and his collaborators, may ke mentioned as one example. The curve given by them is not explained theoretically, perhaps because the quenching temperature could not easily be controlled. When we compare the curve of Rogers with the curves of Fig. 3, the best quenching.temperature range is $800-850^{\circ} \mathrm{C}$. This may be taken as the standard range whenever the coercimeter is used in the steel-works.

Many investigators have attempted to correlate the coercivity with the mechanical properties of steels. Metallurgists like Mathews ${ }^{3}$ have laid much emphasis on the hardness but have found little success. From the formula

$$
H_{c \max .} \simeq 3 / 2 . \lambda \sigma_{i} / I_{8}
$$

derived by Becker ${ }^{4}$, I think that the tensile strength is a good measure of the internal strain of the polycrystalline material. The tensile strengths in $\mathrm{kgm} . / \mathrm{mm} .{ }^{2}$ of carbon steels are therefore plotted along the dotted line in Fig. 1. Only those steels in an annealed state and containing low percentages of manganese and silicon are selected ${ }^{5}$. It seems that there is a parallel relation between the tensile strength and coercivity of the ferromagnetic material.

L. C. TAI.

Sanchi, Ki-Kiang,

Szechuan.

June 12.

${ }^{1}$ International Critical Tables, 6. ${ }^{2}$ Rogers, B. A. Wentzel, K., and Riott, L. R., Trans. Amer. Soc.
Met., 2\%, 175 (1939).

${ }^{3}$ Mathews, J. A., Trans. A.S.S.T., 8, 565 (1925).

- Becker, R., Proc. Phys. Soc., 52, 138 (1940).

- International Critical Tables, 2.

\section{Persistence of Luminosity in Air}

Protracted luminosity occurs naturally in air in at least two forms-aurora borealis and ball lightning. In the case of the aurora, a widely accepted theory is available to account for the energy input which causes excitation. There is, however, considerable doubt as to the corresponding energy mechanism which has been presumed to be necessary to account for the strange stability of ball lightning.

The question arises as to what extent it is necessary to postulate an energy source to explain the sustained luminosity which follows an electrical discharge in air and lasts long enough to be noted by a casual observer. The possibility seems to exist that such a phenomenon can in certain circumstances be described adequately as a purely dissipative process which is simply the aftermath of an intense discharge. The laboratory phenomenon of afterglow is a well-known example of the latter process, as negligible energy is put into the gas by the electrical

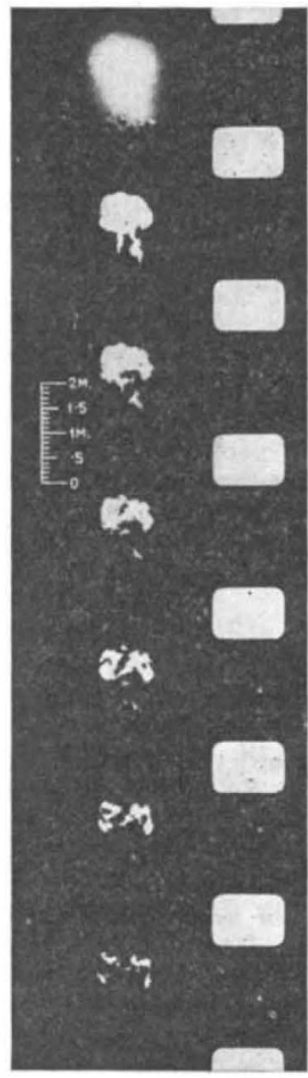

EXTINCTION OF $10 \mathrm{kV}$. 280 AMP. ARC AT NIGHT circuit during the afterglow time. Most of the work on afterglow has been carried out at low pressures where durations of several minutes have been observed, but Meek and Craggs ${ }^{1}$ have recently shown that afterglow lasting approximately 30 microsec. can be produced in argon at atmospheric pressure.

In a previous communication $^{2}$ the appearance of luminous clouds as a sequel to are extinction was reported. This aspect of are extinetion has now been examined further, and cloud durations varying from approximately $0 \cdot I$ to $0 \cdot 3$ sec. have been measured. This phenomenon seems to be a form of afterglow which has some resemblance to ball lightning. It was observed in seven separate tests with currents varying from 90 to $320 \mathrm{amp}$. at 10,000 volts. Great dissimilarities have been noted in regard to the number, shape and rate of shrinkage of the luminous clouds. Some of the tests were carried out at night and recorded by means of a cine-camera which was used without a light filter. A section of the film is reproduced here; in this the are current is considered to have ceased between the first and second frames from the top. The camera speed was 32 frames per second.

This work indicates that the energy dissipation following a heavy electrical discharge in air can be arranged to take place so as to provide luminous masses of gas which persist for an appreciable fraction of a second. It is not unreasonable to expect that in certain cases the phenomenon can be observed with the naked eye.

University College, J. J. O'DOHERTY.

Science Buildings,

Upper Merrion Street, Dublin.

${ }^{1}$ Meek and Craggs, Nature, 152, 538 (1943).

'O'Doherty, Nature, 153, 558 (1944). 